\title{
Tobacco use among Iranian dental students: a national survey
}

H. Keshavarz, ${ }^{1,2}$ M.R. Khami, ${ }^{1}$ A. Jafari ${ }^{1}$ and J.I. Virtanen ${ }^{3,4}$

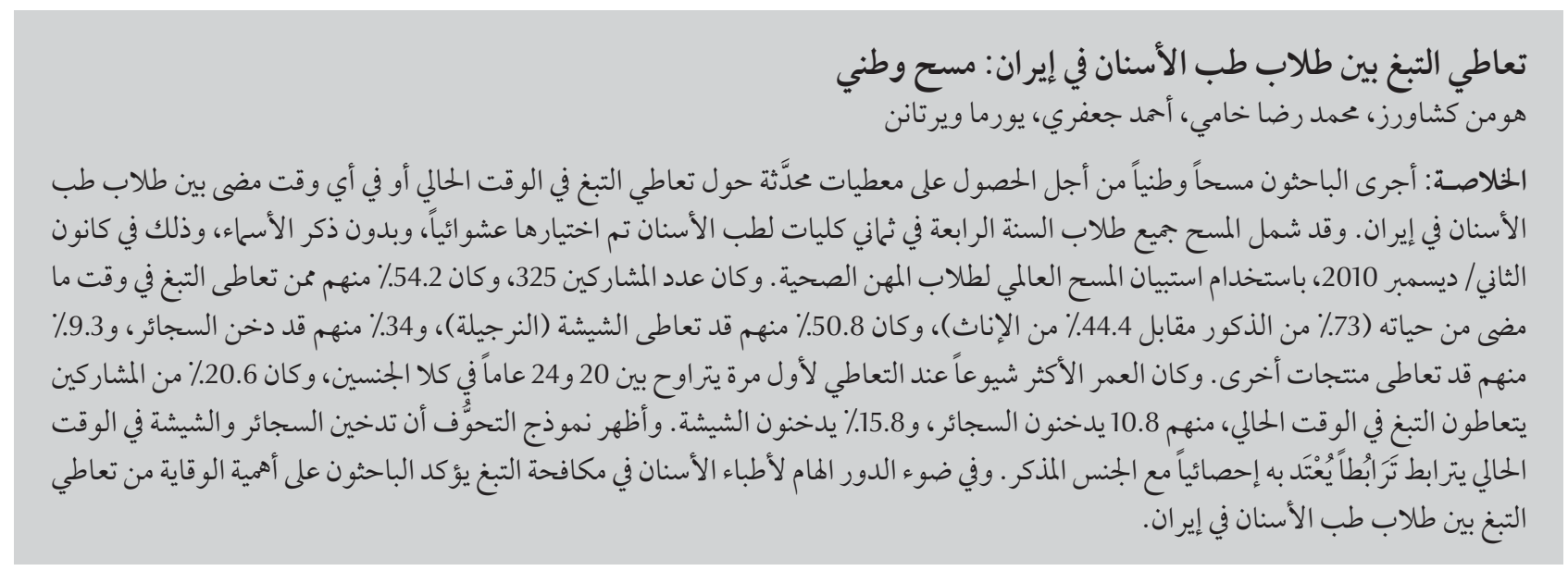

ABSTRACT A national survey was conducted to provide up-to-date data on current and ever use of tobacco among Iranian dental students. All 4th-year students of 8 randomly selected dental schools were surveyed anonymously in December 2010 using the Global Health Professions Student Survey questionnaire. Of 325 participants, 54.2\% were ever users of tobacco products (73.0\% of males versus $44.4 \%$ of females); $50.8 \%$ had used waterpipes, $34.2 \%$ cigarettes and $9.3 \%$ other products. The most common age at first use was $20-24$ years for both sexes. Current tobacco use was reported by $20.6 \%$ of respondents, cigarette smoking by $10.8 \%$ and waterpipe smoking by $15.8 \%$. Regression models showed that current cigarette and waterpipe smoking were significantly associated with male sex but not with type of dental school (state/private). Current waterpipe smoking was also associated with age at first experience. In view of the important role of dentists in tobacco control, the prevention of tobacco use should be stressed among Iranian dental students.

\section{Consommation de tabac des étudiants iraniens en odontologie: enquête nationale}

RÉSUMÉ Une enquête nationale a été menée pour générer des données actualisées sur la consommation de tabac actuelle et passée des étudiants iraniens en odontologie. Tous les étudiants en quatrième année de huit écoles de médecine dentaire sélectionnées aléatoirement ont été interrogés de façon anonyme en décembre 2010 à l'aide du questionnaire de l'enquête mondiale auprès des étudiants des professions de la santé. Sur un total de 325 participants, 54,2 \% avaient déjà utilisé des produits du tabac $(73,0 \%$ des hommes contre 44,4\% des femmes), 50,8 \% avaient déjà utilisé des pipes à eau, 34,2 \% avaient fumé des cigarettes et 9,2 \% avaient consommé d'autres produits. L'âge le plus fréquent lors de la première consommation de tabac se situait entre 20 et 24 ans pour les deux sexes. Parmi les répondants, 20,6\% ont déclaré consommer du tabac au moment de l'étude, 10,8 \% et 15,8 \% ont indiqué fumer des cigarettes et des pipes à eau respectivement. Selon des modèles de régression, la consommation de cigarettes et de pipes à eau au moment de l'étude était nettement associée au sexe masculin mais pas au statut public ou privé des écoles de médecine dentaire fréquentées. La consommation actuelle de pipe à eau était quant à elle associée à l'âge lors de la première expérience. Étant donné le rôle essentiel des dentistes dans la lutte contre le tabagisme, la prévention de la consommation de tabac devrait être mise en exergue auprès des étudiants iraniens en médecine dentaire. 


\section{Introduction}

"Tobacco is the only legally available consumer product which kills people when it is used entirely as intended" [1]. Worldwide, tobacco use is known to be a risk factor for 6 of the 8 leading causes of death [2], and tobaccorelated diseases kill more than 5 million people annually [3]. In developing countries, where more than 900 million smokers out of about 1.3 billion smokers of the world lived in 2003, the situation is even worse than in today's developed countries [4]. While, according to projections, the rate of tobacco-attributable deaths in highincome countries will decline by $9 \%$ between 2002 and 2030, in low- and middle-income countries this rate is estimated to double [3].

As emphasized in the preamble of the World Health Organization (WHO) Framework Convention on Tobacco Control, one of the groups in the best position for controlling tobacco use is health professionals [5]. Among health professionals, oral health professionals have a unique opportunity to fight the tobacco epidemic [6]. Besides dentists, dental students should also receive special attention to prepare them to be involved in tobacco control because they are future dentists and the most open to adopting new professional responsibilities $[7,8]$.

For planning of the curricula and preparing dental students for tobacco control programmes, the first step is to provide baseline data on tobacco use status and attitudes towards tobacco control among them. Quite a few studies have been performed on prevalence of tobacco use and attitudes towards smoking among dental students in various countries [9-14]. Among 7 Eastern Mediterranean Region (EMR) countries, whose dental students were studied at a national level utilizing the Global Health Professions Student Survey (GHPSS), the Islamic Republic of Iran had the second lowest prevalence of current cigarette smoking (range from $2 \%$ for Libya to $32 \%$ for Lebanon) [9]. Regarding current use of tobacco products other than cigarettes, Islamic Republic of Iran ranked fourth (range from 5\% for Sudan to 37\% for Lebanon) [9]. To our knowledge, just 2 national surveys in this country of about 75 million people in 2011 have assessed tobacco use prevalence among Iranian dental students $[9,15]$. These studies included only state-run colleges. The objective of the present study was to provide up-to-date data on tobacco use experience and behaviour among Iranian dental students in both private and state dental schools.

\section{Methods}

\section{Study design and subjects}

A national, cross-sectional study was conducted in December 2010. The target population comprised all Iranian 4th-year dental students. A cluster random sampling method was used to obtain a representative sample. Of all the 18 Iranian dental schools (state and private), in operation for more than 3 years, we selected 8 schools randomly as clusters. The probability of selecting each dental school was proportional to the enrolment of 4th-year students in that same school. In all the schools selected (6 state and 2 private), all 4th-year dental students $(n=385)$ were invited to participate. Participation in the survey was voluntary.

\section{Data collection}

One of the authors (H.K.) distributed a self-administered anonymous questionnaire among the participating students in one of their ordinary classroom settings and collected it immediately after completion by the students. After collecting the completed questionnaires, a small gift was given to some of the participants by lottery.
The data collection instrument in this study was the 2008 version of the GHPSS questionnaire [16]. Originally, GHPSS was designed for evaluating 3rd-year students of 4 disciplines (dentistry, medicine, nursing and pharmacy). Undergraduate dental education in the Islamic Republic of Iran lasts 6 years [17], whereas in most other countries it is 5 years. Thus, comparison of 4th-year Iranian students with the 3rd-year students of the other countries is justifiable. Because of this, in contrast to the single previous study using GHPSS in Islamic Republic of Iran [9], we targeted the 4th-year dental students.

Adjusting the questionnaire to the context of the Islamic Republic of Iran, 3 questions on waterpipe smoking were added to it as recommended by the questionnaire handbook. The modified questionnaire was first translated into Persian and then checked by back translation into English, and checked by experts in dental health. A pilot study was performed in the School of Dentistry, Shahed University (this school was excluded from the sampling frame). A test-retest method with a 2-week interval showed that the agreement of the answers was over $70 \%$ for each question. Cronbach alpha for the prevalence of tobacco use was 0.66 . Based on the students' opinions in the pilot study, some minor changes were made in the appearance of the questionnaire only.

Students first completed some demographic data on age, sex and dental school type (state or private). Experience of using tobacco products (ever tried or experimented with, even 1 or 2 puffs) was determined in 3 separate Yes/No questions about cigarette smoking, waterpipe smoking and other tobacco products [including pipes, chewing tobacco, snuff, bidis (small, hand-rolled cigarettes) and cigars]. Those students who had experience of using any of these tobacco products at 
least once during their lifetimes were classified as ever users.

Age at first experience was determined in 2 further separate questions about cigarette and waterpipe smoking, with 8 alternative answers: I have never smoked, smoked at age $\leq 10,11-15$, $16-17,18-19,20-24,25-29$ or $\geq 30$ years. Merging these categories for age at first experience produced 2 categories for statistical analyses: age $\leq 17$ years and $18+$ years.

The number of days on which students had used tobacco products during the previous 30 days was asked in 3 further separate questions about cigarette smoking, waterpipe smoking and other tobacco products, with 7 alternative answers $(0,1-2,3-5,6-9$, $10-19,20-29$, all 30 days). For statistical analyses, these were merged into 4 categories: $0,1-5,6-19$ and 20-30 days. For each tobacco product, those students who had used it at least once during the previous 30 days were classified as current users.

\section{Statistical methods}

The data were analysed with SPSS for Windows, version 16. The chi-squared test allowed comparison of subgroups and binary logistic regression evaluation of the relationship between the number of days on which cigarette or waterpipe smoking had occurred during the previous month and background factors including sex, age at first experience of tobacco use and dental school type. Corresponding odds ratios (OR) were calculated. The significance level was set at $P<0.05$.

\section{Results}

In total, 325 students (214 females and 111 males) filled in the questionnaires (response rate: $84 \%$ ). Of them $91.7 \%(298 / 325)$ were in the age group 19-24 years, while $6.5 \%(21 / 325)$ were $25-29$ years and $1.8 \%(6 / 325)$ were $\geq 30$ years. Of the students $37.5 \%$ (122/325) came from private schools, in which the proportion of women was significantly higher than the proportion of men (78.7\% versus $21.3 \%)(P$ $<0.001$ ).

More than half the students $(176 / 325,54.2 \%)$ had ever used at least one of the tobacco products during their lifetime (Table 1); about half (50.8\%) had smoked waterpipes, $34.2 \%$ had smoked cigarettes and $9.3 \%$ had used other tobacco products. The most common age for first experience with cigarettes and waterpipes was between ages 20-24 years for both sexes (Table $2)$. Ever use of tobacco was statistically significantly more prevalent among men than among women ( $73.0 \%$ versus 44.4\%) $(P<0.001)$ (Table 1).

Current tobacco use was reported by $67 / 325(20.6 \%)$ of students overall. Current cigarette smoking was practised by $35 / 324$ students (10.8\%), waterpipe smoking by $51 / 323$ (15.8\%), and use of other tobacco products by $7 / 324$ (2.2\%). Current use of tobacco products other than cigarettes was reported by $52 / 325$ students $(16.0 \%)$ (Table 3).

Table 4 shows the students with experience of tobacco use (ever users) by the number of days of use in the previous month (i.e. current users). Among the students with experience of cigarette smoking, significantly more of the males who had experience of tobacco use were current cigarette smokers $(29 / 66,43.9 \%)$ compared with females who were ever-users $(6 / 44$ 13.6\%) $(P<0.001)$ (Table 4). Among the students with experience of waterpipe smoking, men $(29 / 66,43.9 \%)$ had smoked waterpipes significantly more often during the previous month than had women $(6 / 44,13.6 \%)(P=0.004)$. Daily cigarette smoking (on all 30 days in the previous month) was reported by 10/324 (3.1\%) of students. Regarding tobacco products other than cigarettes, none of the students reported daily use. No women had used tobacco products other than cigarettes and waterpipes during the previous 30 days.

In the regression model, current cigarette smoking among those students who were ever cigarette smokers was significantly associated only with male sex $(\mathrm{OR}=5.7,95 \%$ CI: $2.0-15.8)$ (Table 5). The model for current waterpipe smoking among the students who were ever waterpipe smokers showed an association with male sex $(O R=$ 2.9, 95\% CI: 1.4-6.1) and with starting waterpipe smoking at age $\geq 18$ years $(\mathrm{OR}=3.8,95 \%$ CI: $1.7-8.5)$ (Table 5).

\section{Discussion}

The present study investigating tobacco use experience and behaviour among Iranian 4th-year dental students showed

\begin{tabular}{|c|c|c|c|c|c|c|c|}
\hline \multirow[t]{2}{*}{ Ever users of: } & \multicolumn{2}{|c|}{$\begin{array}{c}\text { Both sexes } \\
(n=325)\end{array}$} & \multicolumn{2}{|c|}{$\begin{array}{l}\text { Females } \\
(n=214)\end{array}$} & \multicolumn{2}{|c|}{$\begin{array}{c}\text { Males } \\
(n=111)\end{array}$} & \multirow[t]{2}{*}{$P$-value ${ }^{b}$} \\
\hline & No. & $\%$ & No. & $\%$ & No. & $\%$ & \\
\hline Cigarettes & 111 & 34.2 & 44 & 20.6 & 67 & 60.4 & 0.001 \\
\hline Waterpipes & 165 & 50.8 & 89 & 41.6 & 76 & 68.5 & 0.001 \\
\hline Other tobacco products ${ }^{\mathrm{a}}$ & 30 & 9.3 & 2 & 0.9 & 28 & 25.5 & 0.001 \\
\hline Any kind of tobacco product & 176 & 54.2 & 95 & 44.4 & 81 & 73.0 & 0.001 \\
\hline
\end{tabular}

${ }^{a}$ One male student did not answer this question; ${ }^{b}$-values derived from $\chi^{2}$ test. 


\begin{tabular}{|c|c|c|c|c|c|c|c|c|}
\hline \multicolumn{9}{|c|}{$\begin{array}{l}\text { Table } 2 \text { Ever and current use of cigarettes and waterpipes among } 325 \text { Iranian 4th-year dental students, by age of first } \\
\text { experience }\end{array}$} \\
\hline \multirow{3}{*}{$\begin{array}{l}\text { Age at first experience of smoking } \\
\text { (years) }\end{array}$} & \multicolumn{4}{|c|}{ Experience of use } & \multicolumn{4}{|c|}{ Current use (in previous month) } \\
\hline & \multicolumn{2}{|c|}{ Cigarettes } & \multicolumn{2}{|c|}{ Waterpipes } & \multicolumn{2}{|c|}{ Cigarettes } & \multicolumn{2}{|c|}{ Waterpipes } \\
\hline & No. & $\%$ & No. & $\%$ & No. & $\%$ & No. & $\%$ \\
\hline$\leq 10$ & 10 & 9.1 & 8 & 4.9 & 0 & 0.0 & 1 & 2.0 \\
\hline $11-15$ & 17 & 15.5 & 23 & 14.1 & 4 & 11.4 & 4 & 7.8 \\
\hline $16-17$ & 16 & 14.5 & 34 & 20.9 & 9 & 25.7 & 6 & 11.8 \\
\hline 18-19 & 21 & 19.1 & 39 & 23.9 & 7 & 20.0 & 16 & 31.4 \\
\hline $20-24$ & 40 & 36.4 & 55 & 33.7 & 14 & 40.0 & 23 & 45.1 \\
\hline $25-29$ & 6 & 5.5 & 3 & 1.8 & 1 & 2.9 & 1 & 2.0 \\
\hline $30+$ & 0 & 0.0 & 1 & 0.6 & 0 & 0.0 & 0 & 0.0 \\
\hline Total & $110^{\mathrm{a}}$ & 100.1 & $163^{\mathrm{b}}$ & 99.9 & 35 & 100.0 & 51 & 100.1 \\
\hline
\end{tabular}

${ }^{a}$ One student did not answer this question; ${ }^{b}$ Two students did not answer this question.

that about half the dental students had used at least one tobacco product during their lifetime. The students commonly had their first experience of tobacco use between ages 20 and 24 years. Moreover, about one-fifth of the students were current tobacco users. A significant sex difference existed in the experience of tobacco use as well as in current tobacco use.

We used GHPSS as the data collection instrument [16], and the data were collected according to the Global Tobacco Surveillance System (GTSS) [18] recommendations. This enables us to compare our results with similar studies at the global level. In addition, contrary to the previous research on tobacco use among Iranian dental students $[9,15]$, we included private dental schools in the sampling frame of the study. Since the proportion of dental students studying in the private schools was high, our results provide a more reliable picture of the target population. Moreover, our plan enables a comparison between students in state and private dental schools. Dental students in private colleges commonly pay high tuition fees and often have a higher socioeconomic background than do students in state colleges. This socioeconomic difference could potentially affect the prevalence of tobacco use [19]. However, our results did not support this hypothesis.

Having taken into account the emphasis of the other studies on the importance of controlling waterpipe smoking as a common habit among Iranian dental students [15], Iranian adolescents [20] and women [21], we paid more attention to assessing the prevalence of waterpipe smoking. Since the GTSS recommendations suggest that locally important content can be added to the core questionnaires [18], we evaluated ever and current waterpipe smoking independently by adding 3 questions to our core questionnaire. Thus, the results of this study, in contrast

\begin{tabular}{|c|c|c|c|c|c|c|c|c|}
\hline \multirow[t]{3}{*}{ Variable } & \multirow{2}{*}{\multicolumn{2}{|c|}{$\begin{array}{l}\text { Experience of tobacco } \\
\text { use }\end{array}$}} & \multicolumn{6}{|c|}{ Current use (in previous month) } \\
\hline & & & \multicolumn{2}{|c|}{ Cigarettes } & \multicolumn{2}{|c|}{ Waterpipes } & \multicolumn{2}{|c|}{ Other products } \\
\hline & No. & $\%$ & No. & $\%$ & No. & $\%$ & No. & $\%$ \\
\hline \multicolumn{9}{|l|}{ Sex } \\
\hline Male & 81 & 46.0 & 29 & 82.9 & 32 & 62.7 & 7 & 100.0 \\
\hline Female & 95 & 54.0 & 6 & 17.1 & 19 & 37.3 & 0 & 0.0 \\
\hline \multicolumn{9}{|c|}{ Age group (years) } \\
\hline $19-24$ & 153 & 86.9 & 29 & 82.9 & 45 & 88.2 & 7 & 100.0 \\
\hline $25-29$ & 18 & 10.2 & 5 & 14.3 & 5 & 9.8 & 0 & 0.0 \\
\hline $30+$ & 5 & 2.8 & 1 & 2.9 & 1 & 2.0 & 0 & 0.0 \\
\hline \multicolumn{9}{|c|}{ Type of dental school } \\
\hline State & 108 & 61.4 & 24 & 68.6 & 33 & 64.7 & 3 & 42.9 \\
\hline Private & 68 & 38.6 & 11 & 31.4 & 18 & 35.3 & 4 & 57.1 \\
\hline Total & 176 & 100.0 & 35 & 100.0 & 51 & 100.0 & 7 & 100.0 \\
\hline
\end{tabular}




\begin{tabular}{|c|c|c|c|c|c|c|}
\hline \multirow{2}{*}{$\begin{array}{l}\text { Tobacco product/days of use in previous } \\
\text { month }\end{array}$} & \multicolumn{2}{|c|}{ Both sexes } & \multicolumn{2}{|c|}{ Females } & \multicolumn{2}{|c|}{ Males } \\
\hline & No. & $\%$ & No. & $\%$ & No. & $\%$ \\
\hline \multicolumn{7}{|l|}{ Cigarettes: days of use } \\
\hline 0 & 75 & 68.2 & 38 & 86.4 & 37 & 56.1 \\
\hline $1-5$ & 11 & 10.0 & 3 & 6.8 & 8 & 12.1 \\
\hline $6-19$ & 9 & 8.2 & 0 & 0.0 & 9 & 13.6 \\
\hline $20-30$ & 15 & 13.6 & 3 & 6.8 & 12 & 18.2 \\
\hline Total (ever users) & $110^{\mathrm{a}}$ & 100.0 & 44 & 100.0 & $66^{\mathrm{a}}$ & 100.0 \\
\hline \multicolumn{7}{|l|}{ Waterpipes: days of use } \\
\hline 0 & 112 & 68.7 & 69 & 78.4 & 43 & 57.3 \\
\hline $1-5$ & 44 & 27.0 & 19 & 21.6 & 25 & 33.3 \\
\hline $6-19$ & 7 & 4.3 & 0 & 0.0 & 7 & 9.3 \\
\hline $20-30$ & 0 & 0.0 & 0 & 0.0 & 0 & 0.0 \\
\hline Total (ever users) & $163^{\mathrm{a}, \mathrm{b}}$ & 100.0 & $88^{\mathrm{b}}$ & 100.0 & $75^{\mathrm{a}}$ & 99.9 \\
\hline \multicolumn{7}{|l|}{ Other tobacco products: days of use } \\
\hline 0 & 23 & 76.7 & 2 & 100.0 & 21 & 75.0 \\
\hline $1-5$ & 5 & 16.7 & 0 & 0.0 & 5 & 17.9 \\
\hline $6-19$ & 2 & 6.7 & 0 & 0.0 & 2 & 7.1 \\
\hline $20-30$ & 0 & 0.0 & 0 & 0.0 & 0 & 0.0 \\
\hline Total (ever users) & 30 & 100.0 & 2 & 100.0 & 28 & 100.0 \\
\hline
\end{tabular}

${ }^{a}$ One man did not answer this question; ${ }^{b}$ One woman did not answer this question.

to the previous study using the GHPSS among Iranian dental students [9], drew a clearer picture of the status of waterpipe smoking separately from the status of other tobacco products.

In the present survey, data were collected by a self-administered, anonymous questionnaire. Our high response rate and the survey's anonymity enhance the validity of the results. However, it should be kept in mind that we used no biochemical tests to confirm students' responses. The importance of this point may be clearer when the social unacceptability of tobacco products in Islamic Republic of Iran, especially among women, is taken into account [22].

Our results on the rate of current tobacco use (21\%) are similar to those of Khami et al. (23\%) [15]. They applied a stratified cluster random sampling method to evaluate Iranian senior dental students (The students who are studying in the last 2 semesters of the 6-year undergraduate dental education programme) by randomly selecting 7 state colleges. In these selected colleges, all senior students were invited to participate in the survey. The difference between our findings and those of Khami et al. may be due to the slightly different age of the participants. Our results are in line with those of Warren et al. [9] using the same GHPSS methods ( $11 \%$ versus $10 \%$ for current cigarette smoking and $16 \%$ versus $15 \%$ for current use of tobacco products other than cigarettes).

Nazary et al. investigated the prevalence of cigarette smoking among all male medical sciences students in Semnan, Islamic Republic of Iran [23].

\begin{tabular}{|c|c|c|c|c|}
\hline \multirow[t]{2}{*}{ Variable } & \multicolumn{2}{|c|}{ Current cigarette smokers } & \multicolumn{2}{|c|}{ Current waterpipe smokers } \\
\hline & OR $(95 \% \mathrm{Cl})$ & $P$-value & OR $(95 \% \mathrm{CI})$ & $P$-value \\
\hline Sex (1: female, 2 : male) & $5.7(2.0-15.8)$ & 0.001 & $2.9(1.4-6.1)$ & 0.004 \\
\hline Type of dental school (1: state, 2: private) & $1.4(0.5-3.6)$ & 0.488 & $0.8(0.4-1.8)$ & 0.665 \\
\hline Age at first experience $(0: \leq 17 \mathrm{yrs}, 1: 18+\mathrm{yrs})$ & $1.5(0.6-3.5)$ & 0.407 & $3.8(1.7-8.5)$ & 0.001 \\
\hline Constant & 0.0 & 0.001 & 0.0 & 0.001 \\
\hline
\end{tabular}

Outcome variables: $0=$ no days during the previous 30 days, $1=$ at least once during the previous 30 days.

$O R=$ odds ratio; $C I=$ confidence interval. 
Based on our results, the prevalence of current cigarette smoking among male dental students (26\%) was almost twice as high as the prevalence found in that study (14\%). Iranian medical and nursing students have also been surveyed with the GHPSS questionnaire $[24,25]$. Comparison of our results with the findings of those studies shows that the prevalence of current cigarette smoking was higher among Iranian dental students (11.0\%) than among their medical (5.6\%) and nursing (4.4\%) counterparts. The prevalence of current use of tobacco products other than cigarettes was also higher among Iranian dental students (16\%) than among medical (9.9\%) and nursing (8.8\%) students. Considering the unique position of oral health professionals in tobacco control [6], and the association between smoking and attitudes towards tobacco control [7], this comparison indicates that Iranian dental students should receive special attention to reduce their tobacco use.

Up until 2009, dental students in more than 40 countries were studied with the GHPSS questionnaire at a national level [9]. In only 8 countries was the prevalence of current cigarette smoking lower than the rate we found among Iranian dental students (11.0\%) [9]. However, in our study, the prevalence of current use of tobacco products other than cigarettes was high (16\%) compared with that in most of the other countries [9]. Based on our results, among the EMR countries whose dental students have been studied at a national level utilizing GHPSS ( 7 countries), the ranks of Islamic Republic of Iran for current cigarette smoking and current use of tobacco products other than cigarettes were the same as those that Warren et al. reported in 2011 [9].

That our male dental students used tobacco significantly more commonly than did female students is a finding in harmony with tobacco use assessment among the Iranian lay population [21]. Such a difference can also be seen in other national surveys $[9,15,24,25]$. This phenomenon seems common in other parts of the world, as well; in 6 countries (Czech Republic, Bulgaria, Slovakia, Chile, Uruguay and the People's Democratic Republic of Lao) only current cigarette smoking among female dental students was more frequent than among male students [9]. Regarding tobacco products other than cigarettes, in most countries male dental students used them more often than did female students with the exception of Greece,
Cambodia and People's Democratic Republic of Lao [9].

\section{Conclusion}

Our study reported a high rate of tobacco use experience among Iranian dental students with pronounced sex differences. Specifically, current waterpipe smoking was frequent among these future health professionals. Considering the unique opportunity of oral health professionals to contribute to tobacco control, more emphasis should be upon prevention of tobacco use among Iranian dental students and preparing them to establish tobacco control programmes.

\section{Acknowledgements}

We would like to express our sincere thanks to our colleagues Professor Heikki Murtomaa and Dr Reza Yazdani, who helped us in supportive consultations.

Funding: This research was supported by Tehran University of Medical Sciences and Health Services (grant no. 90-01-69-12893).

Competing interests: None declared.

\section{References}

1. Flannagan M. Smoking and health. In: Walton JN, Barondess JA, Lock S, eds. The Oxford medical companion. Oxford, Oxford University Press, 1994:908.

2. WHO report on the global tobacco epidemic, 2008: The MPOWER package. Geneva, World Health Organization, 2008.

3. Mathers CD, Loncar D. Projections of global mortality and burden of disease from 2002 to 2030. PLoS Medicine, 2006, 3:e442.

4. The world health report: shaping the future. Geneva, World Health Organization, 2003.

5. Framework Convention on Tobacco Control. Geneva, World Health Organization, 2003.

6. Petersen PE, ed. The World Oral Health Report 2003: Continuous improvement of oral health in the 21st century-the approach of the WHO Global Oral Health Programme. Geneva, World Health Organization, 2003.

7. Tobacco or oral health: an advocacy guide for oral health professionals. Lowestoft, England, World Dental Federation Press, 2005.
8. McCartan B, McCreary C, Healy C. Attitudes of Irish dental, dental hygiene and dental nursing students and newly qualified practitioners to tobacco use cessation: a national survey. European Journal of Dental Education, 2008, 12:17-22.

9. Warren $\mathrm{CW}$ et al. Tobacco use, exposure to secondhand smoke, and cessation counseling training of dental students around the world. Journal of Dental Education, 2011, 75:385-405.

10. Pizzo G et al. Attitudes of Italian dental and dental hygiene students toward tobacco-use cessation. European Journal of Dental Education, 2010, 14:17-25.

11. Dumitrescu AL. Attitudes of Romanian dental students towards tobacco and alcohol. Journal of Contemporary Dental Practice, 2007, 8:64-71.

12. Dumitrescu AL. Tobacco and alcohol use among Romanian dental and medical students: a cross-sectional questionnaire survey. Oral Health and Preventive Dentistry, 2007, 5:279-284.

13. Smith DR, Leggat PA. An international review of tobacco smoking among dental students in 19 countries. International Dental Journal, 2007, 57:452-458. 
14. Vanobbergen J et al. Dental students' attitude towards antismoking programmes: a study in Flanders, Belgium. European Journal of Dental Education, 2007, 11:177-183.

15. Khami MR et al. Smoking and its determinants among Iranian dental students. Medical Principles and Practice, 2010, 19:390-394.

16. Core questions. Global Health Professional Students Survey (GHPSS) 2008 (http://nccd.cdc.gov/GTSSData/Ancillary/ Documentation.aspx?SUID $=3 \& D O C T=1$, accessed 3 June 2013).

17. Pakshir HR. Dental education and dentistry system in Iran Medical Principles and Practice, 2003, 12(Suppl. 1):56-60.

18. Warren CW et al. Evolution of the Global Tobacco Surveillance System (GTSS) 1998-2008. Global Health Promotion, 2009, 16(Suppl.):4-37.

19. Nagelhout GE et al. Trends in socioeconomic inequalities in smoking prevalence, consumption, initiation, and cessation between 2001 and 2008 in the Netherlands. Findings from a national population survey. BMC Public Health, 2012, 12:303.

20. Kelishadi R et al.; CASPIAN Study Group. Smoking behavior and its influencing factors in a national-representative sample of Iranian adolescents: CASPIAN study. Preventive Medicine, 2006, 42:423-426.

21. Meysamie A et al. Pattern of tobacco use among the Iranian adult population: results of the national Survey of Risk Factors of Non-Communicable Diseases (SuRFNCD-2007). Tobacco Control, 2010, 19:125-128.

22. Sarraf-Zadegan $\mathrm{N}$ et al. Tobacco use among Iranian men, women and adolescents. European Journal of Public Health, 2004, 14:76-78.

23. Nazary AA et al. Smoking among male medical sciences students in Semnan, Islamic Republic of Iran. Eastern Mediterranean Health Journal, 2010, 16:156-161.

24. Warren CW et al. Tobacco use, exposure to secondhand smoke, and training on cessation counseling among nursing students: cross-country data from the Global Health Professions Student Survey (GHPSS), 2005-2009. International Journal of Environmental Research and Public Health, 2009 6:2534-2549.

25. Warren CW et al. Tobacco use, exposure to secondhand smoke, and cessation counseling among medical students: cross-country data from the Global Health Professions Student Survey (GHPSS), 2005-2008. BMC Public Health, 2011, 11:72.

\section{WHO Framework Convention on Tobacco Control: Guidelines for Implementation of Article 5.3, Articles 8 to 14 (ARABIC)}

This book contains the guidelines adopted by the Conference of the Parties. These seven guidelines cover a wide range of provisions of the WHO Framework Convention on Tobacco Control, such as: the protection of public health policies with respect to tobacco control from commercial and other vested interests of the tobacco industry; protection from exposure to tobacco smoke; packaging and labelling of tobacco products; and tobacco advertising, promotion and sponsorship; and demand reduction measures concerning tobacco dependence and cessation.

These guidelines are intended to help Parties to meet their obligations under the respective provisions of the Convention. They reflect the consolidated views of Parties on different aspects of implementation, their experiences and achievements, and the challenges faced. The guidelines also aim to reflect and promote best practices and standards that governments would benefit from in the treaty-implementation process.

Further information about this and other WHO publications is available at: http://apps.who.int/bookorders/anglais/ home1.jpp?sesslan=1 